\title{
Clinicopathological features and Borrmann classification associated with HER2-positive in primary gastric cancer
}

This article was published in the following Dove Press journal:

Clinical and Experimental Gastroenterology

\author{
Xiaomin Dai ${ }^{1}$ \\ Xijiong Zhang ${ }^{2}$ \\ Jin $\mathrm{Yu}^{1,2}$
}

'Department of Pathology, Zhejiang Hospital, Hangzhou, Zhejiang, People's

Republic of China; ${ }^{2}$ Department of Pathology, The No.I People's Hospital of Pinghu, Jiaxing, Zhejiang, People's

Republic of China
Correspondence: Jin Yu

Department of Digestion, The No.I

People's Hospital of Pinghu, 500 Sangang

Road, Donghu Street, Pinghu, Jiaxing,

Zhejiang, People's Republic of China

Tel +86 I 380672 279|

Email I380672279I@I39.com
Purpose: Human epidermal growth factor receptor 2 (HER2) assesment is important for patients with advanced gastric cancer (GC) to determine trastuzumab therapy is being considered. A study was performed to evaluate the rate of HER2 positivity in patients with primary gastric cancer and to assess the relationship between HER2-positive and Borrmann classification.

Patients and methods: Four hundred and sixty-one patients with gastric or gastroesophageal junction cancer were confirmed as having adenocarcinoma between 2005 and 2016 . HER2 status was assessed using immunohistochemistry (IHC) and/or fluorescence in situ hybridization (FISH). Tissues were considered to be HER2-positive when assessment revealed either an IHC score of $3+$ or IHC score $2+$ accompanied by a positive FISH result. Results: The HER2-positive rate was significantly higher in men than in women (19\% vs $9 \% ; p=0.006$ ). In our study, HER2-positive gastric tumors with differentiated histology were significantly higher. The proportion of HER2-positive gastric tumors of Borrmann classification III or IV was significantly higher than tumors classified as I or II.

Conclusions: HER2-positive gastric cancer tends to be associated with male gender, differentiated histology, and Borrmann tumor classification of III or IV.

Keywords: HER2 gastric cancer, FISH, immunohistochemistry, Borrmann classification

\section{Introduction}

Gastric cancer is one of the major malignant tumors that seriously threaten human life and health, and the fatality rate in the world is the second highest among all tumor. ${ }^{1}$ With the deepening research on the molecular mechanism of tumor, molecular targeted therapy has attracted much attention. Human epidermal growth factor receptor 2 (HER2) encodes a trans-membrance tyrosine kinase receptor that drives tumorigenesis pathways such as cell survival, invasion, metastasis, and angiogenesis. ${ }^{2,3}$ HER2 protein immunohistochemical expression and gene amplification were first identified in around $15-30 \%$ of women with brast carcinoma, ${ }^{4-6}$ and subsequently were similarly demonstrated in other carcinomas, most notably gastric and oesophageal adenocarcinomas. ${ }^{7-9}$ HER2 plays an important role in the occurrence and development of gastric cancer, has gradually become a research hotspot of targeted therapy. ${ }^{10}$ Currently, trastuzumab combined with chemotherapy has been officially approved for first-line treatment of HER2 positive advanced gastric cancer, but the clinical significance of many factors affecting HER2 detection and HER2 gene heterogeneity is still not completely clear. ${ }^{11-13}$ 
Although some small-scale studies have not demonstrated the prognostic properties of HER2, a large number of studies indicate that HER2 is a negative prognostic factor, showing more aggressive biological behavior and higher frequencies of recurrence in HER2-positive tumors. ${ }^{3}$ Several studies have reported the clinicopathological features of HER2 expression in gastric cancer. ${ }^{14}$ However, limited studies have described the association between HER2 status and Bormann classification. In this study, we assessed the clinicopathological features and Bormann classification of HER2-positive gastric cancer.

\section{Materials and methods}

\section{Clinicopathological data and histological specimens \\ Study population}

We retrospectively analyzed the medical records and tumor tissues at the NO.1 people's hospital of PingHu from January 2005 to April 2016. All patients presented the following criteria in our study: (1) the presence of primary adenocarcinoma, and the diagnosis was confirmed by endoscopic biopsy or surgical specimen, (2) patients without chemoradiotherapy and have no other synchronous malignancy, (3) complete clinicopathological data were obtained. Exclusion criteria included the patients refusing to allow researchers to use their clinical data and tissue samples.

The clinicopathological data of all patients were obtained from our hospital information system. Clinicopathologic characteristics, including gender, age, primary tumor location, tumor size, histological classification, Bormann classification, lymph node metastasis and T stage (AJCC 7th edition). The clinicopathological staging (TNM) of the primary tumors was determined according to the International Union Again Cancer, ${ }^{15}$ histological type according to Lauren's classification and differentiation grade based on WHO classification.

\section{Ethical considerations}

This study was approved by Medical Ethic Committee of No.1 people's Hospital of Pinghu (No.2018-51). This study was performed in compliance with the Declaratin of Helsinki, the CIOMS International Guidelines for Ethical Review of Epidemiological Studies, as well as applicable China laws. The patient conset to review their medical records was not required because the written informed conset was very unlikely obtained in this retrospective study. The data could be assessed only by authorized health professionals using their own staff codes. Patient's name and identification number were omitted and redered anonymous before data analysis.

\section{Borrmann classification}

The most commonly used classification method for gastric cancer is Borrmann classification, which is mainly based on the appearance and growth state of the tumor. Based on the the Borrmann criteria, which has satisfactory results according to the clinical statistics, GCs are divided into four groups.

Borrmann I, Mainly exogenous growth, usually broadbased polypoid carcinomas with protruding; Borrmann II, with a central, bowl-shaped ulcer in the center and elevated margins, with a relatively clear boundary between the cancer and the surrounding environment; Borrmann III, centrally ulcerating carcinoma without a rige, elevated margins and not distince from the surrounding environment; Borrmann IV, diffuse tumor infiltration of the gastric wall. ${ }^{16}$ Borrmann types were obtained from endoscopist and pathologist in available cases.

\section{HER2 evaluation}

Immunohistochemistry (IHC)

In this study, HER2 expression comprised 461 patients was detected by IHC. IHC staining was carried out using an anti-HER2/NEU antibody (Beijing Zhongshan Golden Bridge Biotechnology Co., Ltd, Beijing, China) against HER2 on a Ventana Benchmark XT automatic staining system, according to the manufacturer's instructions. Staining criteria was evaluated using the $0-3+$ scale according to the modified IHC scoring system adopted in the ToGA study. ${ }^{17}$ At least five positive cancer cells within a cluster for endoscopic biopsy sample or a $10 \%$ of neoplastic cells positive in a surgical specimen are necessary for this scoring system. Figure 1 showed immunohistochemistry expression for HER2 from negative to $1+, 2+$ and $3+$ in gastric cancer. The coincidence rate of immunohistochemical evaluation of the 2 observers was more than $90 \%$. If there is any objection, the final results was determined by consensus after review.

\section{Fluorescence in situ hybridization (FISH)}

When the result of IHC was 2+, the amplification level of HER2 was detected. PathVysion DNA Probe kit was used for the analysis of FISH according to the manufacturer's protocol. The positive results from FISH was defined as a HER2: CEP17 ratio $\geq 2.0 .{ }^{18}$ Example of HER2 FISH positive and negative were shown in Figure 2. According to the standards 

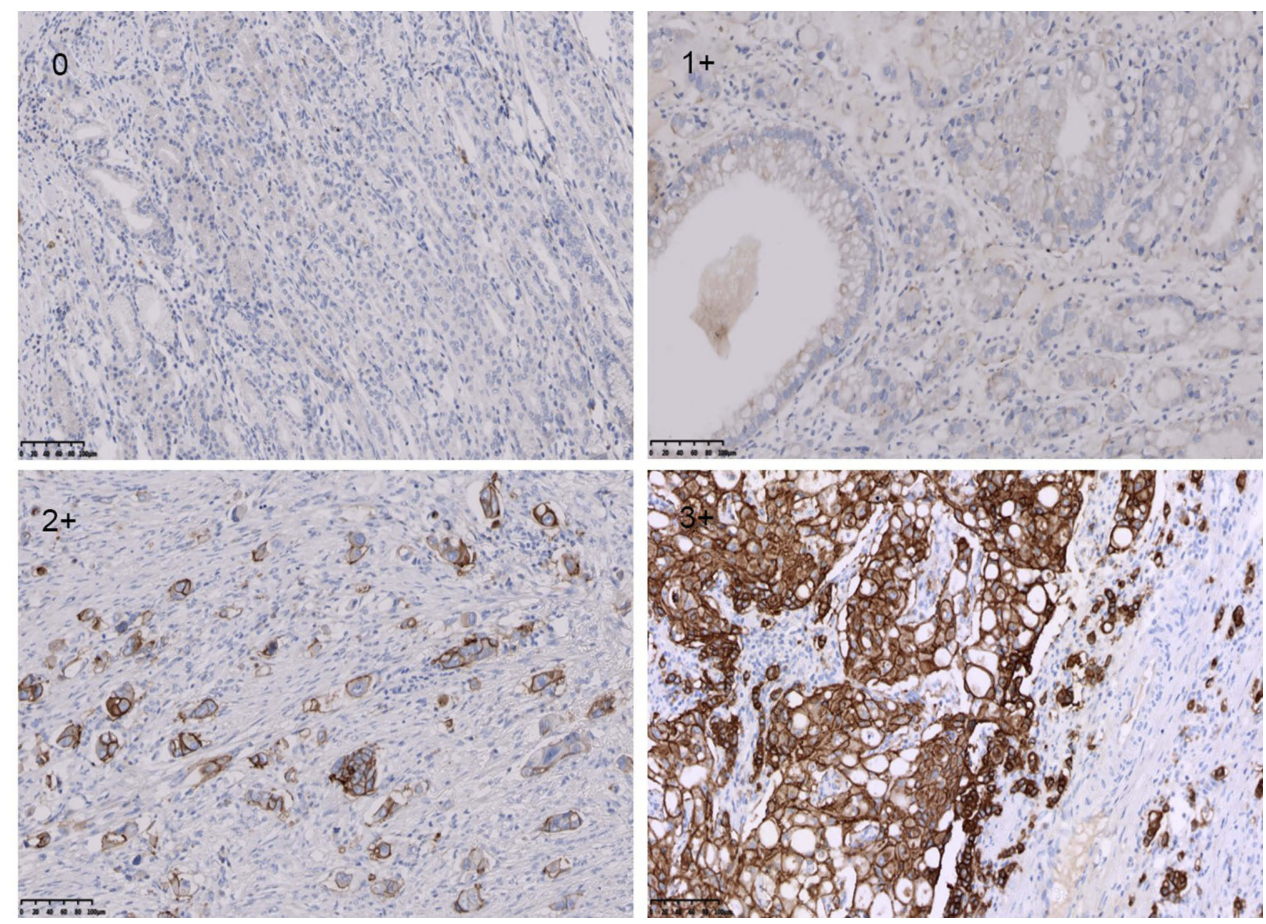

Figure I Human epidermal growth factor receptor 2 (HER2) expression by IHC (magnification $\times 200$ ).

of the European Medicines Agency, HER2-positive was defined as any case of IHC $3+$ or IHC $2+$ with a positive FISH result, while any case of IHC 0 , IHC $1+$ or IHC $2+$ with a negative FISH result is considered HER2-negative.

\section{Statistical analysis}

Demographic and tumor characteristics of the patients were summarized by descriptive statistical methods. The chi-squared test was used to test the statistical significance of the correlation between each categorical variable and the HER status. Continuous variables were grouped for this analysis. A $p$-value of $<0.05$ was considered statistically significant. Higher $p$-values indicate higher confidence in rejecting the null hypothesis for no association. SPSS software (Version 22.00, SPSS, Chicago, IL) was used for statistical analysis.

\section{Results}

\section{Patient and clinicopathological features}

A total of 461 patients were enrolled in the study. The main patient characteristics have been described in detail and are summarized in Table 1. Surgical samples and

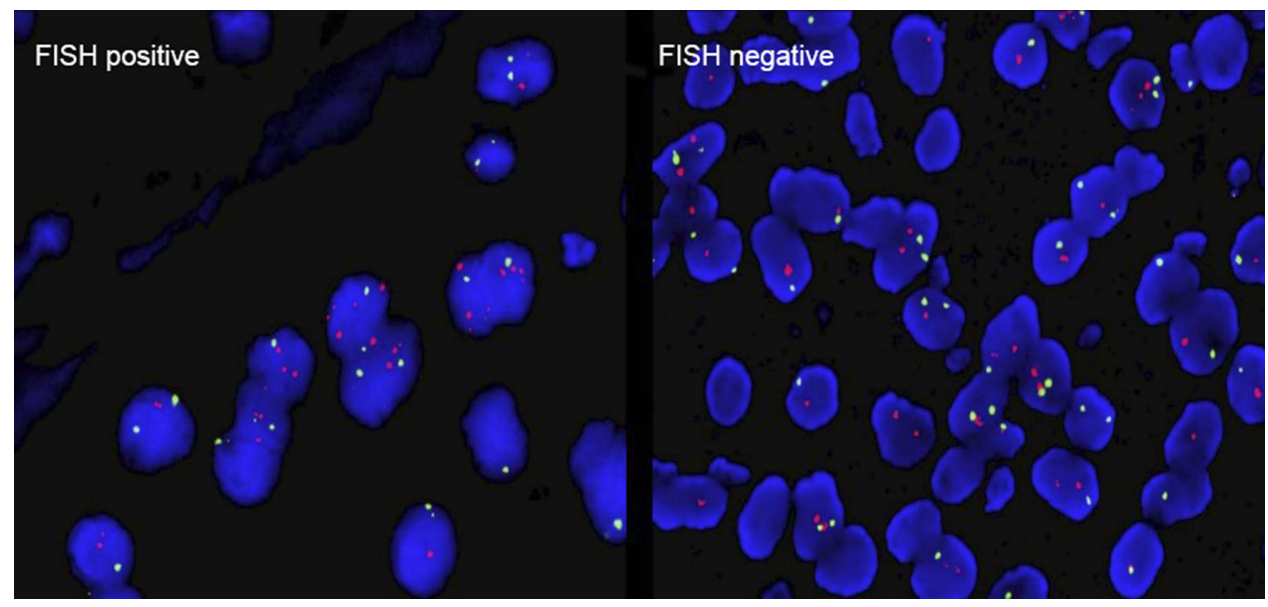

Figure 2 Human epidermal growth factor receptor 2 (HER2) status by FISH (magnification $\times 200$ ). 
endoscopic biopsy samples were obtained from different patients. The patients had an average age of 60 years (range 32-81 years) and were predominantly male (67.2\%). Most tumor samples were obtained from biopsy samples and most tumors were located in the middle and lower stomach. The TNM staging classification of all of the tumors indicated that 152 patients $(33 \%)$ were Stage I-II and 309 patients $(67 \%)$ were Stage III-IV. The proportion of gastric tumors with Borrmann classification 2 or 3 was higher than tumors with Borrmann classification 1 or 4 (Table 1).

\section{HER2 levels}

Therefore, a total of 461 gastric cancer tissue specimens were evaluated using IHC and/or FISH for their HER2 status in this study. HER2 status was assessed in 99 surgical samples and 362 endoscopic biopsy samples (Table 2). Of the 461 patients, 270, 59, 86, and 46 were HER2 IHC 0, IHC 1+, IHC 2+, and IHC 3+, respectively. FISH analysis was performed on 25 surgical samples and 61 biopsy samples, and HER2 amplification was observed in 33\% (28/86) of cases. In total, the HER2-positive rate was $16 \%$ (74/461). Among the 74 HER2-positive gastric cancer cases, 46 cases were IHC $3+$, and the remaining 28 cases were interpreted as IHC $2+$ and FISH positive.

\section{Association of HER2 status with clinicopathplogical features}

The association between HER 2 expression and clinicopathological parameters are shown in Table 3. The HER2-positive

Table I Clinical and pathological features of the study cases

\begin{tabular}{|c|c|c|c|c|}
\hline & & Total & Surgical samples & Endoscopic biopsy samples \\
\hline Enrolled patients, $\mathrm{n}$ & & 461 & 99 & 362 \\
\hline \multirow[t]{2}{*}{ Gender } & Male & 310 & 65 & 245 \\
\hline & Female & $|5|$ & 34 & 117 \\
\hline \multirow[t]{2}{*}{ Age } & $\leq 60$ & 117 & 33 & 84 \\
\hline & $>60$ & 344 & 66 & 278 \\
\hline \multirow[t]{4}{*}{ Primary tumor location } & Gastroesophageal junction & 45 & 12 & 33 \\
\hline & Upper third & 70 & 15 & 55 \\
\hline & Middle third & 230 & 42 & 188 \\
\hline & Lower third & 116 & 30 & 86 \\
\hline \multirow[t]{2}{*}{ Tumor size, $\mathrm{cm}$} & $<5$ & 286 & 51 & 235 \\
\hline & $\geq 5$ & 175 & 48 & 127 \\
\hline \multirow[t]{3}{*}{ Histological type } & Intestinal type & 175 & 47 & 128 \\
\hline & Diffuse type & 171 & 41 & 130 \\
\hline & Mixed type & 115 & 11 & 104 \\
\hline \multirow[t]{2}{*}{ Histological grade } & Well-differentiated & 241 & 59 & 182 \\
\hline & Poorly differentiated & 220 & 40 & 180 \\
\hline \multirow[t]{4}{*}{ Borrmann classification } & I & 29 & 9 & 20 \\
\hline & II & 128 & 26 & 102 \\
\hline & III & 197 & 44 & 153 \\
\hline & IV & 96 & 19 & 87 \\
\hline \multirow[t]{2}{*}{ Lymph node metastasis } & Present & 324 & 76 & 248 \\
\hline & Absent & 137 & 23 & 114 \\
\hline \multirow[t]{2}{*}{ TNM stages } & $I+I I$ & 152 & 31 & 121 \\
\hline & III+IV & 309 & 68 & 241 \\
\hline
\end{tabular}

Table 2 HER2 status assessed by IHC and FISH in 46I primary gastric carcinomas (bioptic and surgical specimens)

\begin{tabular}{|l|l|l|l|l|l|l|l|l|}
\hline & Tot & IHC 0 & IHC I+ & \multicolumn{1}{l|}{ IHC 2+ } & IHC 3+ & HER2 negative (\%) & HER2 positive (\%) \\
\hline & & & & FISH- & FISH+ & & & \\
Biopsy specimens & 362 & 220 & 47 & $4 I$ & 20 & 34 & $308(85 \%)$ & $54(15 \%)$ \\
Surgical specimens & 99 & 50 & 12 & 17 & 8 & 12 & $79(80 \%)$ & $20(20 \%)$ \\
Tot & $46 I$ & 270 & 59 & 66 & 37 & 46 & $387(84 \% c)$ & $74(16 \%)$ \\
\hline
\end{tabular}


rate in male patients $(60 / 310 ; 19 \%)$ was higher than that seen in female patients $(14 / 151 ; 9 \% ; p=0.006)$. The proportion of HER2-positive gastric tumors with a well-differentiated histology was significantly higher than that in tumors with an poorly differentiated histology (49 vs $25 \%$, respectively; $p=0.009$ ). Among samples with Borrmann classification subtyes, the HER2-positive rate of Borrmann 3 was particularly high $(22 \%, 44 / 197 ; p=0.001)$ when compared with other subtyes. The presence of HER2 overexpression was not influenced by tumor location $(p=0.372)$.

\section{HER2 expression status and assessment of bormann classification}

\section{Surgical resection samples}

The detail assessments of HER2 IHC expression with Bormann subtypes of 99 surgical resection samples was shown in Table 4. According to the IHC results, 25 surgical samples were IHC $2+$ for HER2 status. FISH was performed in these samples and 8 cases were found to be positive. We made comparisons of HER2 status among subgroups divided based on the Bormann classification (Figure 3). The rate were $0 \%, 7 \%, 30 \%$ and $17 \%$ when the Bormann type were I, II, III and IV, respectively. The results showed that HER2 positive rate did not exhibit significant differences among these subgroups, indicating that the HER2 IHC expression was not associated with Bormann classification.

\section{Endoscopic biopsy samples}

The association between HER2 IHC status and Bormann classification was analyzed in 362 biopsy samples in Table 5 . The results showed the differences in HER2 expression status according to Boramnn classification. According to the IHC results, 61 surgical samples were IHC 2+ for HER2. FISH was carried out in these samples and 20 cases were FISH positive. The HER2-positive rates from Bormann I, II, III, and IV were $10 \%, 7 \%, 20 \%$ and $16 \%$, respectively. HER 2 positivity (IHC 3 + and IHC $2+/$ FISH + ) was observed in 54/362 primary tumors in biopsy specimens. The assessment showed that HER2 IHC positive rate exhibited significant differences among these subgroups (Figure 4), indicating that the HER2-positive rate was associated with Bormann classification $3(P=0.001)$.

\section{Discussion}

Gastric cancer (GC) is the second most common cause of cancer-related deaths worldwide; median survival is

Table 3 HER2 positivity according to clinicopathological factors of patients with gastric cancer

\begin{tabular}{|c|c|c|c|c|}
\hline \multicolumn{2}{|l|}{ Factor } & \multirow{2}{*}{$\begin{array}{l}\text { HER2-positive }(n=74) \\
74\end{array}$} & \multirow{2}{*}{$\begin{array}{l}\text { HER2-negative }(n=387) \\
387\end{array}$} & \multirow[t]{2}{*}{$p$-Value } \\
\hline & & & & \\
\hline \multirow[t]{2}{*}{ Gender } & Male & 60 & 250 & 0.006 \\
\hline & Female & 14 & 137 & \\
\hline \multirow[t]{2}{*}{ Age } & $\leq 60$ & 23 & 94 & 0.219 \\
\hline & $>60$ & 51 & 293 & \\
\hline \multirow[t]{4}{*}{ Primary tumor location } & Gastroesophageal junction & II & 34 & 0.372 \\
\hline & Upper third & 10 & 60 & \\
\hline & Middle third & 33 & 197 & \\
\hline & Lower third & 20 & 96 & \\
\hline \multirow[t]{2}{*}{ Tumor size, cm } & $<5$ & 43 & 243 & 0.447 \\
\hline & $\geq 5$ & 31 & 144 & \\
\hline \multirow[t]{3}{*}{ Histological type } & Intestinal type & 37 & 138 & 0.062 \\
\hline & Diffuse type & 21 & 150 & \\
\hline & Mixed type & 16 & 99 & \\
\hline \multirow[t]{2}{*}{ Histological grade } & Well-differentiated & 49 & 192 & 0.009 \\
\hline & Poorly differentiated & 25 & 195 & \\
\hline \multirow[t]{4}{*}{ Borrmann classification } & I & 2 & 27 & 0.001 \\
\hline & II & 9 & 121 & \\
\hline & III & 44 & 153 & \\
\hline & IV & 17 & 88 & \\
\hline \multirow[t]{2}{*}{ Lymph node metastasis } & Present & 56 & 268 & 0.268 \\
\hline & Absent & 18 & 119 & \\
\hline \multirow[t]{2}{*}{ TNM stages } & $1+\|$ & 31 & 121 & 0.075 \\
\hline & III+IV & 43 & 266 & \\
\hline
\end{tabular}


Table 4 Relationship pf Borrmann classification to HER2 IHC status in surgical $(P=0.171)$

\begin{tabular}{|l|l|l|l|l|l|}
\hline \multirow{2}{*}{ HER2 IHC Status } & \multicolumn{4}{|l|}{$\begin{array}{l}\text { Borrmann classification } \\
\text { assessment }\end{array}$} \\
\cline { 2 - 5 } & 1 & 2 & 3 & 4 & \\
\hline 0 & 6 & 9 & 26 & 8 & 61 \\
1 & 2 & 6 & 3 & 2 & 12 \\
2 & 1 & 10 & 7 & 6 & 25 \\
3 & 0 & 3 & 8 & 2 & 12 \\
Total & 9 & 28 & 44 & 18 & 99 \\
\hline
\end{tabular}

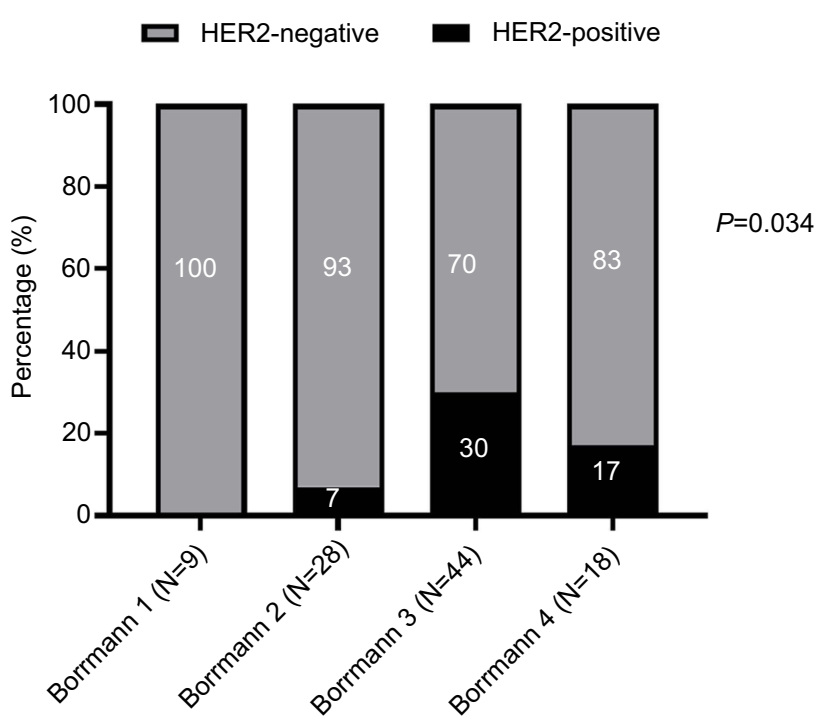

Figure 3 Association of HER2 status with different tumor subtypes in surgical resection samples.

Table 5 Relationship pf Borrmann classification to HER2 IHC status in biopsy $(p=0.001)$

\begin{tabular}{|l|l|l|l|l|l|}
\hline \multirow{2}{*}{ HER2 IHC Status } & \multicolumn{4}{|l|}{$\begin{array}{l}\text { Borrmann classification } \\
\text { assessment }\end{array}$} \\
\cline { 2 - 5 } & I & 2 & 3 & 4 & \\
\hline 0 & 11 & 63 & 78 & 68 & 220 \\
1 & 2 & 10 & 30 & 5 & 47 \\
2 & 5 & 21 & 31 & 4 & 61 \\
3 & 2 & 8 & 14 & 10 & 34 \\
Total & 20 & 102 & 153 & 87 & 362 \\
\hline
\end{tabular}

10-12 months in advanced cases. ${ }^{1}$ Even with the most recent chemotherapy treatment, survival is typically estimated at $<1$ year. ${ }^{19}$ Chemothotherapy is the standard treatment for the maiority of GC patients, however a subset of patients who harbor HER2 amplification are candidates for HER2-targeted therapy. ${ }^{9}$ In the ToGA trial, the addition of trastuzumab to chemotherapy improved overall survival (OS) among patients whose tumors tested HER2 positive. $^{20}$

In 1986, some gastric cancers were found to exhibit amplified human epidermal growth factor receptor 2 (HER2) using immunohistochemistry. ${ }^{3}$ In the following decade, it has been reported HER2 overexpress or gene amplification depending on tumor location and histopathological classification. ${ }^{13}$ Notably, up to $37 \%$ of AGCs show amplification of the genes related to receptor tyrosine kinase/Ras signaling pathways; this has been corroborated by the recently proposed molecular classification by The Cancer Genome Atlas. ${ }^{14}$ The evaluation of HER2 in biopsy specimens were as important as in surgical specimens, because many gastric cancer patients are in advanced stages and can not be surgically removed.

The percentage of HER2-positive tumors ranged from 4 to $53 \%$, with a median rate of $18 \%$ in a systematic review of HER2 status in gastric cancer patients based on publication. ${ }^{21-23}$ In the presents study, HER2-positive rate was evident in $16 \%$ of patients. In the ToGA study, $54.6 \%$ of IHC $2+$ cases were found to be FISH positive, ${ }^{17,20}$ but in our study, out of 461 samples, 132(29\%) were collected for gene amplification testing, out of which 74(56\%) samples showed gene amplification, and $35.9 \%$ tumors with IHC $2+$ score showed c-erbB-2 gene amplification.

In our trial, $24.4 \%$ of GEJ tumors were found to be HER2-positive. Similar HER2 overexpression rates were reported in recent global clinical trials, where the rate of HER2 overexpression was found to be 16-29\%. ${ }^{14}$ Yasuhiro Oono et al demonstrated that HER2-positive gastric cancer is found more frequently in the EGJ. In the ToGA study with a large number of patients, the HER2-positive rates were $32 \%$ in GEC and $18 \%$ in GC, respectively. However, based on our results we found that the incidence of HER2 positivity was found to be greater (24.4\%) in GEJ than in gastric body cancers (15.1\%), but this finding did not reach statistical significance. Our clinical study showed the presence of HER2 overexpression in tumors was not influenced by tumor location. The discordance observed might have been caused by different samples and technical variables.

Several recent studies have demonstrated that the HER2positive rate appears to be higher in well-differentiated histology tumors than poor-differentiated histology tumors, and this difference was statistically significant $(P=0.036) .^{24}$ This is consistent with previous studies suggesting that age, sex, and the growth pattern of tumors were indirectly related to 


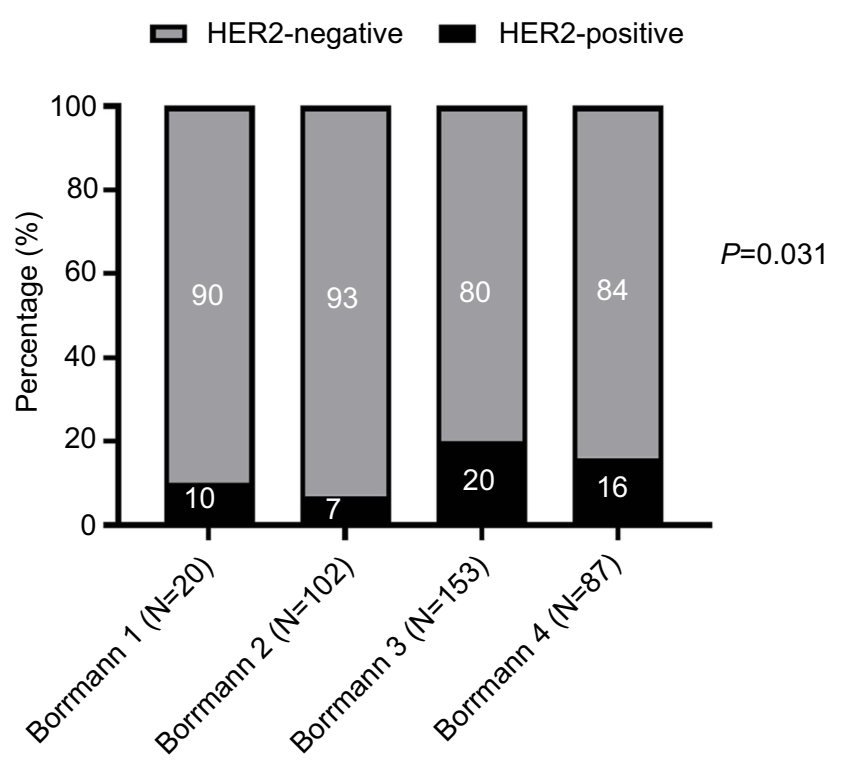

Figure 4 Association of HER2 status with different tumor subtypes in endoscopic biopsy samples.

the likehood of HER2 overexpression in gastric cancer. ${ }^{25} \mathrm{We}$ analyzed the association between HER2 expression and well differentiated tumors, our study also showed a significant association $(P=0.009)$. Futhermore, studies have reported that HER2 expression is more frequent in male patients compared to female patients. Our results statistically indicated that HER2 expression was more common in male patients in our study (19\%) than that seen in female patients $(9 \% ; p=0.006)$.

The relationship between HER2 overexpression and Bormann classification in gastric cancer has not been widely studied to date. In the present study, the proportion of HER2-positive was correlated with Borrmann classification in patients with gastric cancer. The results indicated that the proportion of HER2-positive gastric tumors with a Bormann classification III or IV was significantly higher than in tumors with a Bormann classification I or II, and this finding reached statiscal significance. The proportions of HER2-positive tumors with Borrmann classification I, II, III and IV were $0,7,30$ and $17 \%$, respectively. The HER2-positive rate of Bormann classification III tumors with differentiated histology was particularly high at $48 \%$. Yasuhiro Oono et al recently reported that Borrmann classification I tumors with a differentiated histology exhibited a particularly higher HER2-positive rate than tumors with a Borrmann classification II, III or IV. However, their study focused on HER2 expressed in Japan patients, several factors might explain this discrepancy, such as difference in race, varying samples processing and type of antibody and/or assay method. The contributing factors for HER overexpression in Borrmann III type gastric cancer are quite complex and we believe further exploration of this finding is warranted.

HER2 gene amplification in gastric cancer would lead to more aggressive and proliferative tumor. A number of recent reports have assessed the HER2 status in GC and its importance as a prognostic and predictive factor for targeted therapy. ${ }^{9,24}$ In the ToGA trial, it was concluded that that trastuzumab should be used to treat patients with Her2/neu overexpression, which was consistent with the previous results and analysis. ${ }^{17}$ The result of the phase III ToGA trial suggested that trastuzumab combined with cisplatin and fluropyrimidine chemotherapy is the standard treatment for patients with HER2-positive advanced gastric cancer. ${ }^{26}$ Based on these studies, trastuzumab therapy is being considered in patients with advanced or metastatic adenocarcinoma and IHC is recommended to assess tumor HER2 overexpression.

Our study has several limitations, this is a single-center study rather than multi-center investigation. Therefore, results for HER2 expression might be limited. The discordance observed in association between HER2 expression and Borrmann classification, it might have been caused by heterogeneity of gastric cancer. Based on this findings, it is important to recognize the expansive growth pattern of the tumor, and endoscopist should perform sufficient biopsy specimens carefully to avoid a false negative finding of the HER2 expression. In summary, we presented a clinicopathological study analysing HER2 status in primary gastric cnacer. Furthermore, a prospective study is needed to validate the results of our retrospective analysis.

\section{Acknowledgment}

The authors thank all the people who helped with this study.

\section{Disclosure}

The authors have declared that no competing interests exist in this work.

\section{References}

1. Farin K, Dores GAM, Anderson WF. Patterns of cancer incidence, mortality, and prevalence across five continents: defining priorities to reduce cancer disparities in different geographic regions of the world. J Clin Oncol. 2006;24(14):2137-2150. doi:10.1200/JCO.2005.05.2308 
2. Coussens L, Yang-Feng TL, Liao YC, et al. Tyrosine kinase receptor with extensive homology to EGF receptor shares chromosomal location with neu oncogene. Science. 1985;230 (4730):1132-1139.

3. Akiyama T, Sudo C, Ogawara H, Toyoshima K, Yamamoto T. The product of the human c-erbB-2 gene: a 185-kilodalton glycoprotein with tyrosine kinase activity. J Sci. 1986;232(4758):1644-1646. doi:10.1126/science.3012781

4. Hetzel DJ, Wilson TO, Keeney GL, Roche PC, Cha SS, Podratz KC. HER-2/neu expression: a major prognostic factor in endometrial cancer. J Gynecologic Oncol. 1992;45(1):86-87. doi:10.1016/00908258(92)90539-U

5. Kaptain S, Tan LK, Chen BJ. Her-2/neu and breast cancer. Diagn Mol Pathol. 2001;10(3):139-152.

6. Eltze E, WãLfing C, Von SD, Piechota H, Buerger H, Hertle L. Cox-2 and Her2/neu co-expression in invasive bladder cancer. Int J Oncol. 2005;26(6):1525-1531.

7. Schuell B, Gruenberger T, Scheithauer W, Zielinski C, Wrba F. HER 2/neu protein expression in colorectal cancer. BMC Cancer. 2006;6 (1): 123.

8. Reichelt U, Duesedau P, Mch T, et al. Frequent homogeneous HER-2 amplification in primary and metastatic adenocarcinoma of the esophagus. Mod Pathol. 2007;20(1):120.

9. Fujita TJLO. Targeted therapy for gastric cancer. The Lancet Oncology. 2012;13(3):377-389.

10. Chua TC, Merrett ND. Clinicopathologic factors associated with HER2-positive gastric cancer and its impact on survival outcomesa systematic review. Int $J$ Cancer. 2012;130(12):2845-2856. doi:10.1002/ijc.26292

11. Hofmann M, Stoss O, Shi D, et al. Assessment of a HER2 scoring system for gastric cancer: results from a validation study. Histopathology. 2010;52(7):797-805.

12. Marx AH, Simon R, Sauter GJHP. HER-2 amplification is highly homogenous in gastric cancer-reply. Hum Pathol. 2010;41 (2):305-306.

13. Lee S, de Boer WB, Fermoyle S, Platten M, Kumarasinghe MPJH. Human epidermal growth factor receptor 2 testing in gastric carcinoma: issues related to heterogeneity in biopsies and resections. Histopathology. 2011;59(5):832-840. doi:10.1111/j.1365-2559.2011.04017.x

14. Baykara M, Benekli M, Ekinci O, et al. Clinical significance of HER2 overexpression in gastric and gastroesophageal junction cancers. Journal of Gastrointestinal Surgery. 2015;19(9):1-7.
15. Montes HZ. TNM classification of malignant tumors, 7th edition. International Journal of Radiation Oncology Biology Physics. 2010;78(4):1278. doi:10.1016/j.saa.2010.12.077

16. Borchard FJH. Classification of gastric carcinoma. HepatoGastroenterology. 1990;37(2):223-232.

17. Bang YJ, Van CE, Feyereislova AJL. Trastuzumab in combination with chemotherapy versus chemotherapy alone for treatment of HER2-positive advanced gastric or gastro-oesophageal junc tion cancer(ToGA): aphase 3, open-label, randomised controlled trial. Lancet. 2010;376(9742):687-697. doi:10.1016/S0140-6736(10) 61121-X

18. Rüschoff J, Hanna W, Bilous M, et al. HER2 testing in gastric cancer: a practical approach. Mod Pathol. 2012;25(5):637-650. doi:10.1038/ modpathol.2011.198

19. Ohtsu A. Chemotherapy for metastatic gastric cancer: past, present, and future. $J$ Gastroenterol. 2008;43(4):256-264. doi:10.1007/ s00535-008-2177-6

20. Jørgensen JT, Hersom M. HER2 as a prognostic marker in gastric cancer - a systematic analysis of data from the literature. $J$ Cancer. 2012;3(1):137-144. doi:10.7150/jca.4090

21. Dong IP, Yun JW, Park JH, et al. HER-2/neu amplification is an independent prognostic factor in gastric cancer. Dig Dis Sci. 2006;51(8):1371-1379. doi:10.1007/s10620-005-9057-1

22. Shuyi W, Gang Z, Liangdong C, Bin XJ. Effect of HER-2/neu over-expression on prognosis in gastric cancer: a meta-analysis. Asian Pacific Journal of Cancer Prevention. 2011;12(6):1417-1423.

23. Gorana G, Janez L, Juan Antonio C, et al. HER2 in gastric cancer: an immunohistochemical study on tissue microarrays and the coressponding whole-tissue sections with a supplemental fish study. Pathology \& Oncology Research. 2013;19(4):855-865.

24. Gravalos C, Jimeno AJ. HER2 in gastric cancer: a new prognostic factor and a novel therapeutic target. Ann Oncol. 2008;19 (9):1523-1529. doi:10.1093/annonc/mdn169

25. Aizawa M, Nagatsuma AK, Kitada $K$, et al. Evaluation of HER2-based biology in 1,006 cases of gastric cancer in a Japanese population. Gastric Cancer. 2014;17(1):34.

26. Yung-Jue B, Eric VC, Andrea F, et al. Trastuzumab in combination with chemotherapy versus chemotherapy alone for treatment of HER2-positive advanced gastric or gastro-oesophageal junction cancer (ToGA): a phase 3, open-label, randomised controlled trial. Lancet. 2010;376(9742):687-697. doi:10.1016/S0140-6736(10) 61121-X
Clinical and Experimental Gastroenterology

\section{Publish your work in this journal}

Clinical and Experimental Gastroenterology is an international, peerreviewed, open access, online journal publishing original research, reports, editorials, reviews and commentaries on all aspects of gastroenterology in the clinic and laboratory. This journal is indexed on American Chemical Society's Chemical Abstracts Service (CAS).
The manuscript management system is completely online and includes a very quick and fair peer-review system, which is all easy to use. Visit http://www.dovepress.com/testimonials.php to read real quotes from published authors. 